\title{
Infective endocarditis in children with congenital heart disease: comparison of selected features in patients with surgical correction or palliation and those without
}

\author{
T KARL, D WENSLEY, J STARK, M DE LEVAL, P REES, J F N TAYLOR \\ From the Thoracic Unit, The Hospital for Sick Children, Great Ormond Street, London
}

SUMMARY The diagnostic and prognostic features of 44 episodes of infective endocarditis in 42 children with congenital heart disease were reviewed. Endocarditis occurred in 18 patients who had not had surgical correction or palliation of the defect (non-operated group). There were 26 episodes in 24 patients who had been treated surgically (operated group) (16 open and eight closed cardiac operations). Endocarditis occurred soon after open heart surgery in eight patients and as a late complication in the other 16. It recurred in two patients (operated group). Invasive monitoring and low cardiac output were consistent features in those patients who had endocarditis soon after open heart surgery whereas dental treatment was a common feature in nonoperated cases and after closed cardiac operations. Late cases of endocarditis after open heart surgery had various microbiological features that were not typical of infection after dental problems. Gram positive infections occurred in non-operated patients and in those who had had closed cardiac operations. The group that had open heart surgery had infections caused by Gram positive, Gram negative, and anaerobic bacteria and fungi. Fever, anaemia, leucocytosis, and positive blood cultures were the only consistent findings. Vegetations were seen in nine of 12 patients at cross sectional echocardiography. All 12 (four non-operated, one closed, and seven open cases) needed acute surgical treatment. The mortality from infective endocarditis was $17 \%$ for non-operated cases, $0 \%$ for those who had had closed heart surgery, and $50 \%$ for those who had had open heart surgery.

Infective endocarditis after open heart surgery differs from that in the other subgroups in terms of microbiology, source of infection, and outcome and its early diagnosis depends on a thorough investigation of minimal symptoms and signs.

Infective endocarditis is an infrequent but serious disease in infants and children. The risk of infective endocarditis is greatest in children with congenital heart lesions, whether or not the defect has been treated surgically. We retrospectively reviewed cases of infective endocarditis treated in the Thoracic Unit of The Hospital for Sick Children, Great Ormond Street, London, between 1965-1983 to determine the clinical and pathological differences

Requests for reprints to Dr J F N Taylor, Thoracic Unit, The Hospital for Sick Children, Great..Ormond Street, .London.. WCIN 3JH.

Accepted for publication 24 February 1987 between infective endocarditis occurring in the various subgroups studied. This information will be useful in achieving earlier diagnosis and better treatment of infective endocarditis in patients who have surgical correction or palliation of congenital heart lesions. The clinical signs and symptoms of endocarditis in these patients may differ from those normally associated with subacute bacterial endocarditis.

\section{Patients and methods}

We reviewed 44 episodes of infective endocarditis in 42 patients. The age at the time of diagnosis of endo- 
carditis ranged from three days to 16 years (mean (SD) 7.8(4.7) years). Twenty four patients had had operations to correct or palliate their congenital defect and 18 had not. Two of the operated patients had two episodes of infective endocarditis. The episodes were grouped according to the temporal relation between infective endocarditis and previous operation and the type of operation, if any. Early postoperative infective endocarditis was defined as that occurring within 30 days after operation and late infective endocarditis occurred any time after that. Patients with non-operated congenital heart disease were known to have a congenital heart lesion before the episode of infective endecarditis or were diagnosed as having one at the time of presentation. Operations were either complete corrections performed on cardiopulmonary bypass or palliative procedures performed without bypass. For the purposes of this study, patients who had balloon atrial septostomy were included in the group with nonoperated congenital heart disease whereas all the patients who had other palliative operations were included in the group that had operation without cardiopulmonary bypass.

The data were analysed by a $\chi^{2}$, Fisher's exact, or two-tailed Student's $t$ test as appropriate, and the relative risks of death from infective endocarditis were calculated for various clinical and pathological features. ${ }^{1}$

\section{Results}

Tables 1-6 summarise the data and the various characteristics for each group. The underlying cardiac lesions in these patients produced a spectrum of cyanotic and non-cyanotic problems in all the subgroups (table 1). The interval between operation and infective endocarditis was $<30$ days in eight patients in the cardiopulmonary bypass group (mean (SD) 6.5 (5.2) days). The remaining cases in the cardiopulmonary bypass and palliative groups occurred much later (mean (SD) 3.2 (3.5) years) and was con-

Table 1 Diagnosis and previous operations in patients with infective endocarditis

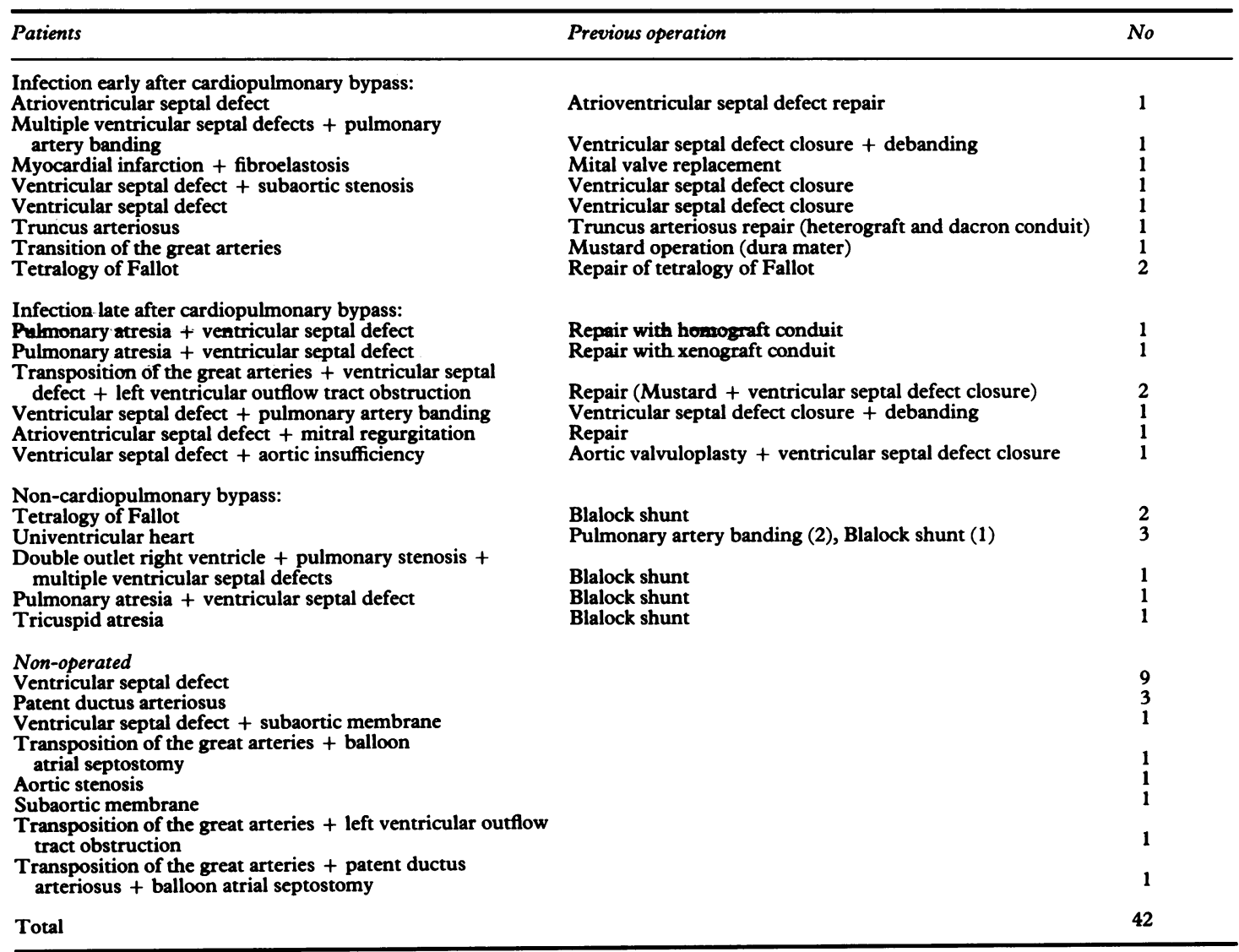


sistent with different aetiological factors in these groups. The mean age of operated and non-operated patients was similar $(\mathrm{p}<0.2)$. The mean interval between operation and infective endocarditis was similar for the non-cardiopulmonary bypass and cardiopulmonary bypass groups $(p>0 \cdot 1)$ despite the higher number of early cases in the cardiopulmonary bypass group (table 2). Cases occurring within 30 days of cardiopulmonary bypass were associated with invasive monitoring and low cardiac output; both these features were unusual in noncardiopulmonary bypass patients.

The source of infection in endocarditis is difficult to prove in any individual case, even if the same organism is cultured from blood and other tissues. Table 3 gives the sources suspected in our cases. In all the early cases after cardiopulmonary bypass there was at least one suspected source for the septicaemia. Most of these were related directly to the surgical procedure and concomitant invasive monitoring. Four of these eight patients had a low cardiac output requiring inotropic support for more than 24 hours after operation, and three had acute renal failure (one requiring peritoneal dialysis). Two of the eight had residual ventricular septal defects after closure. These findings contrasted with those in the other groups of patients. In these groups no source for the septicaemia was identified in $40-60 \%$. For the cardiopulmonary bypass cases only one patient had a suspected dental source for the septicaemia. Dental problems were identified in a significantly $(p<0.001)$ higher proportion of the non-cardiopulmonary bypass $(4 / 8)$ and nonoperated cases $(9 / 18)$.

Blood cultures were positive in all but three episodes in this study in patients in whom the diagnosis was confirmed at operation or necropsy. Although monomicrobial Gram positive infections were predominant (31 out of 41 episodes) the frequency of Gram negative, fungal, and polymicrobial infections was significantly higher in the cardiopulmonary bypass cases $(p<0.001)$. The most frequently isolated organisms belonged to the streptococcus viridans group (including Streptococcus mitis and Streptococcus sanguis) (17/41), and Staphylococcus aureus (14/41). Fungi were isolated in two cases, occurring coincidentally with viridans infection in the same patient (table 4).

Table 5 summarises the symptoms, signs, and laboratory findings in the patients we reviewed. No individual symptom was present consistently in all groups-the norm was a constellation of non-

Table 2 Distribution of patients with infective endocarditis and the interval between operation and infection

\begin{tabular}{lcccrc}
\hline & No & Episodes & Mean interval & Mean age (yr) & Mortality (\%) \\
\hline Early cases after CPB & 8 & 8 & $6 \cdot 6$ days & 5.0 & 50 \\
Late cases after CPB & 8 & 10 & $30 \cdot 6$ mnth & $11 \cdot 3$ & 50 \\
Non-CPB & 8 & 8 & $48 \cdot 3$ mnth & $5 \cdot 9$ & 0 \\
Non-operated & 18 & 18 & - & $7 \cdot 7$ & 17 \\
Total & 42 & 44 & - & $7 \cdot 8$ & 26 \\
\hline
\end{tabular}

CPB, cardiopulmonary bypass.

Table 3 Suspected sources for septicaemia in patients with infective endocarditis

\begin{tabular}{|c|c|c|c|c|}
\hline Suspected source & Early cases after $C P B$ & Late cases after $C P B$ & Non-CPB & Non-operated \\
\hline Central lines & 8 & - & - & - \\
\hline Intra-aortic balloon & 1 & - & - & - \\
\hline Wound abscess & 1 & - & - & - \\
\hline Peritoneal dialysis catheter & 2 & - & - & - \\
\hline Tracheostomy wound & 1 & - & - & - \\
\hline Necrotising enterocolitis & 1 & - & - & - \\
\hline Umbilical artery catheter & 1 & - & - & - \\
\hline Tonsillitis & - & 1 & 1 & - \\
\hline Sinusitis & - & 1 & - & - \\
\hline Femoral arteriovenous fistula & - & 1 & - & - \\
\hline Pneumonia & - & - & 1 & 2 \\
\hline Skin laceration & - & - & - & 1 \\
\hline Cardiac catheterisation & - & - & - & 1 \\
\hline Dental infection & - & 1 & 2 & 5 \\
\hline Cutting second tooth & - & - & - & 1 \\
\hline Dental instrumentation (with antibiotics) & - & - & 2 & - \\
\hline Dental instrumentation (without antibiotics) & - & - & - & 3 \\
\hline No source identified & - & 6 & 3 & 7 \\
\hline Total & 15 & 10 & 9 & 20 \\
\hline
\end{tabular}

CPB, cardiopulmonary bypass. 
specific complaints. Physical examination on the other hand showed fever in nearly every case (39/44) at presentation. A new or changed murmur was found in six out of ten late cases after cardiopulmonary bypass. This was a less frequent finding in early cases after cardiopulmonary bypass, in noncardiopulmonary bypass cases, and in non-operated cases (3/8, 1/8, $7 / 18$ respectively); and is not significant $(p>0 \cdot 1)$. New or increasing congestive heart failure was most common $(p<0.01)$ in cases presenting soon after cardiopulmonary bypass. Signs traditionally associated with endocarditis were too uncommon to be helpful in early diagnosis. Cross sectional echocardiography was useful in the 12 patients undergoing this examination and showed vegetations in nine.

Complications of the infection itself or of treatment or both were frequent in all groups (mean 0.63-1.9 per episode) (table 6). For the entire group 45 complications occurred in 31 cases (mean 1.18 per episode).

This study did not include a detailed analysis of antibiotic treatment. Patients on our unit received treatment after consultation with microbiologists,

Table 4 Micro-organisms isolated from blood in patients with infective endocarditis

\begin{tabular}{|c|c|c|c|c|c|}
\hline Organism & $\begin{array}{l}\text { Early cases after } C P B \\
(8)^{\star}\end{array}$ & $\begin{array}{l}\text { Late cases after } C P B \\
(10)^{\star}\end{array}$ & $\begin{array}{l}\text { Non-CPB } \\
(8)^{\star}\end{array}$ & $\begin{array}{l}\text { Non-operated } \\
(18)^{\star}\end{array}$ & $\begin{array}{l}\text { Total } \\
(44)^{\star}\end{array}$ \\
\hline $\begin{array}{l}\text { Staphylococcus aureus } \\
\text { Streptococcus viridans group } \\
\text { Streptococcus mitis + Str sanguis } \\
\text { Streptococcus viridans group + } \\
\text { Candia albicans } \\
\text { Streptococcus pneumoniae } \\
\text { Corynebacterium } \\
\text { Escherichia coli } \\
\text { Pseudomonas aeruginosa } \\
\text { Klebsiella } \\
\text { Bacillus fragilis + Proteus vulgaris } \\
\text { Tinea capitatum } \\
\text { Candida guillermondi } \\
\text { None Isolated }\end{array}$ & $\begin{array}{l}\frac{2}{-} \\
\frac{-}{1} \\
\frac{1}{2} \\
\frac{1}{2}\end{array}$ & $\begin{array}{l}3 \\
1 \\
- \\
- \\
- \\
- \\
1 \\
1 \\
1\end{array}$ & $\begin{array}{l}\frac{3}{-} \\
\frac{1}{-} \\
\frac{-}{-} \\
\frac{-}{1}\end{array}$ & $\begin{array}{l}9 \\
5 \\
1 \\
\frac{1}{1} \\
\frac{1}{-} \\
- \\
-\end{array}$ & $\begin{array}{r}14 \\
9 \\
1 \\
1 \\
1 \\
1 \\
1 \\
2 \\
2 \\
1 \\
1 \\
1 \\
3\end{array}$ \\
\hline
\end{tabular}

«Total episodes.

Table 5 Clinical and pathological features of infective endocarditis

\begin{tabular}{|c|c|c|c|c|}
\hline & $\begin{array}{l}\text { Early cases after } C P B \\
\left(8^{\star}\right)\end{array}$ & $\begin{array}{l}\text { Late cases after } C P B \\
\left(10^{\star}\right)\end{array}$ & $\begin{array}{l}\text { Non-CPB } \\
\left(8^{\star}\right)\end{array}$ & $\begin{array}{l}\text { Non-operated } \\
\left(18^{\star}\right)\end{array}$ \\
\hline $\begin{array}{l}\text { Symptom: } \\
\text { Vomiting } \\
\text { Headache } \\
\text { Anorexia } \\
\text { Malaise } \\
\text { Seizure } \\
\text { Weight loss } \\
\text { Abdominal pain } \\
\text { Rigors } \\
\text { Sweating } \\
\text { Arthralgia } \\
\text { Failure to thrive } \\
\text { No symptoms }\end{array}$ & $\begin{array}{l}- \\
- \\
\overline{-} \\
\overline{-} \\
- \\
-\end{array}$ & $\begin{array}{l}\frac{2}{2} \\
2 \\
\frac{1}{1} \\
\frac{3}{2} \\
\frac{1}{-}\end{array}$ & $\begin{array}{l}- \\
1 \\
3 \\
- \\
- \\
- \\
- \\
1 \\
1 \\
1\end{array}$ & $\begin{array}{l}4 \\
3 \\
3 \\
3 \\
1 \\
2 \\
1 \\
1 \\
- \\
-1 \\
-\end{array}$ \\
\hline $\begin{array}{l}\text { Signs: } \\
\text { Fever } \\
\text { Change in murmur } \\
\text { Congestive heart failure (new } \\
\text { or increased) } \\
\text { Pulmonary embolus } \\
\text { Systemic embolus } \\
\text { Splenomegaly } \\
\text { Cutaneous signs } \\
\text { Acute abdomen } \\
\text { Lymphadenopathy }\end{array}$ & $\begin{array}{l}8 \\
3 \\
8 \\
\frac{1}{-} \\
- \\
-\end{array}$ & $\begin{array}{l}8 \\
6 \\
3 \\
3 \\
1 \\
2 \\
2 \\
- \\
-\end{array}$ & $\begin{array}{l}7 \\
1 \\
5 \\
\frac{2}{2} \\
\frac{2}{1}\end{array}$ & $\begin{array}{r}16 \\
7 \\
5 \\
3 \\
2 \\
3 \\
1 \\
1 \\
-\end{array}$ \\
\hline $\begin{array}{l}\text { Laboratory data: } \\
\text { Anaemia } \\
\text { Leucocytosis } \\
\text { Abnormal urine sediment } \\
\text { Chest } x \text { ray change } \\
\text { Change in electrocardiogram }\end{array}$ & $\begin{array}{l}8 \\
8 \\
1 \\
8 \\
\end{array}$ & $\begin{array}{l}6 \\
6 \\
1 \\
3 \\
1\end{array}$ & $\begin{array}{l}5 \\
4 \\
2 \\
5 \\
\end{array}$ & $\begin{array}{r}14 \\
12 \\
6 \\
11 \\
1\end{array}$ \\
\hline
\end{tabular}

^Total episodes. 
cardiologists, surgeons, and pharmacists; and in patients who had operation we assumed that appropriate medical treatment had failed. Table 7 summarises the indications for surgical intervention in patients undergoing treatment for infective endocarditis. Late cases after cardiopulmonary bypass were the most likely to require surgery during the initial stage of medical treatment $(p<0.01)$. Five patients in the non-cardiopulmonary bypass group and four in the non-operated group had cardiac operations after successful medical treatment for infective endocarditis, not for complications of infective endocarditis per se but rather for the underlying congenital lesions. Overall, 12 of 44 episodes of infective endocarditis had a fatal outcome (27\% mortality). The $50 \%$ mortality for infective

Table 6 Complications occurring during treatment of infective endocarditis

\begin{tabular}{|c|c|c|c|c|}
\hline Complication & $\begin{array}{l}\text { Early cases after } C P B \\
\left(8^{\star}\right)\end{array}$ & $\begin{array}{l}\text { Late cases after } C P B \\
\left(10^{\star}\right)\end{array}$ & $\begin{array}{l}\text { Non-CPB } \\
\left(8^{\star}\right)\end{array}$ & $\begin{array}{l}\text { Non-operated } \\
\left(18^{\star}\right)\end{array}$ \\
\hline $\begin{array}{l}\text { Renal failure } \\
\text { Septic shock } \\
\text { Gastrointestinal bleed } \\
\text { Disseminated intravascular coagulation } \\
\text { Aortic insufficiency } \\
\text { Mitral insufficiency } \\
\text { Cerebrovascular accident } \\
\text { Aortic aneurysm } \\
\text { Pulmonary insufficiency } \\
\text { Pulmonary embolus } \\
\text { Pulmonary artery aneurysm } \\
\text { Superior vena cava obstruction } \\
\text { by vegetation } \\
\text { Splenic infarction } \\
\text { Neutropenia } \\
\text { Nephritis (drug) } \\
\text { Left ventricular outflow tract obstruction } \\
\text { by vegetation } \\
\text { Coronary embolus } \\
\text { Myocardial abscess } \\
\text { Conduit obstruction } \\
\text { Homograft valve destruction } \\
\text { Death } \\
\text { No complications }\end{array}$ & $\begin{array}{l}2 \\
1 \\
1 \\
1 \\
1 \\
1 \\
1 \\
1 \\
- \\
- \\
- \\
- \\
- \\
- \\
- \\
- \\
-\end{array}$ & $\begin{array}{l}- \\
- \\
- \\
- \\
-3 \\
- \\
3 \\
1 \\
-1 \\
- \\
1 \\
1 \\
1 \\
1 \\
5 \\
2\end{array}$ & 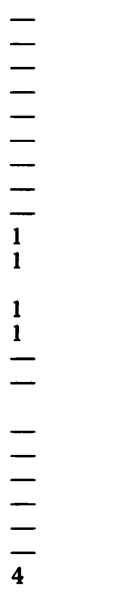 & $\begin{array}{l}- \\
Z- \\
- \\
\bar{Z} \\
\frac{2}{-} \\
\overline{1} \\
- \\
- \\
\overline{1} \\
2 \\
- \\
- \\
- \\
- \\
5\end{array}$ \\
\hline
\end{tabular}

^Total episodes.

Table 7 Surgical indications during treatment of infective endocarditis (44 episodes, 42 patients)

\begin{tabular}{|c|c|c|}
\hline Indication & Operation & Patients \\
\hline $\begin{array}{l}\text { Early cases after CPB: } \\
\text { Aortic aneurysm (cannulation site) } \\
\text { Aortic valve perforation } \\
\text { Aortic dissection, residual ventricular septal defect } \\
\text { No surgery, patient survived } \\
\text { No surgery, patient died }\end{array}$ & $\begin{array}{l}\text { Resection of aneurysm } \\
\text { Aortic valve replacement } \\
\text { Repair of dissection and ventricular septal defect }\end{array}$ & $\begin{array}{l}1 \\
1 \\
2 \\
3\end{array}$ \\
\hline $\begin{array}{l}\text { Late cases after CPB: } \\
\text { Cerebral emboli } \\
\text { Sepsis-continued } \\
\text { Pulmonary emboli } \\
\text { Pulmonary artery aneurysm } \\
\text { Conduit obstruction } \\
\text { No surgery, patient survived } \\
\text { No surgery, patient died }\end{array}$ & $\begin{array}{l}\text { Resection of vegetation } \\
\text { Various } \\
\text { Excision of vegetation } \\
\text { Resection of pulmonary artery aneurysm } \\
\text { Conduit replacement }\end{array}$ & $\begin{array}{l}1 \\
4 \\
1 \\
1 \\
1 \\
1 \\
1\end{array}$ \\
\hline $\begin{array}{l}\text { Non-CPB: } \\
\text { Multiple pulmonary emboli } \\
\text { No surgery, patient survived }\end{array}$ & Excision of vegetations & $\begin{array}{l}1 \\
7\end{array}$ \\
\hline $\begin{array}{l}\text { Non-operated: } \\
\text { Aortic insufficiency + vegetation } \\
\text { Pulmonary emboli + tricuspid vegetation } \\
\text { Aortic insufficiency + vegetation } \\
\text { Aortic insufficiency + vegetation } \\
\text { No surgery, patient survived }\end{array}$ & $\begin{array}{l}\text { Aortic valve replacement } \\
\text { Ventricular septal defect closure, tricuspid valve } \\
\text { leaflet excision } \\
\text { Aortic valve replacement }+ \text { residual subaortic } \\
\text { membrane } \\
\text { Aortic valve plication + excision of vegetation }\end{array}$ & $\begin{array}{r}1 \\
1 \\
1 \\
1 \\
14\end{array}$ \\
\hline
\end{tabular}


Table 8 Relative risk of death in infective endocarditis

\begin{tabular}{ll}
\hline & $\begin{array}{l}\text { Factor by which } \\
\text { risk of death } \\
\text { was increased }\end{array}$ \\
\hline Clinical feature & $8 \cdot 36$ \\
\hline Low cardiac output, congestive heart failure & $4 \cdot 33$ \\
Post-cardiopulmonary bypass & $4 \cdot 2$ \\
Renal failure & $3 \cdot 14$ \\
Non-staphylococcus/streptococcus infection & $2 \cdot 85$ \\
Systemic embolus & $2 \cdot 70$ \\
Surgery required during treatment & $1 \cdot 26$ \\
Conduit infection & \\
\hline
\end{tabular}

endocarditis after open heart surgery was significantly higher than mortality rates in the other groups $(p<0.01)$. This mortality reflects the summation of the individual risk factors identified in table 8, which are placed in order of adverse effect. These have been analysed in a mathematical format designed to isolate one risk from another. ${ }^{1}$ This analysis showed that an individual with infective endocarditis in whom cardiac failure with a low output develops was just over eight times more likely to die from infective endocarditis as a patient without this complication.

\section{Discussion}

The large numbers of children surviving palliative or corrective operations for congenital heart disease constitute a population with a new set of risk factors and a more virulent form of infective endocarditis. Thus effective prophylaxis and early diagnosis of infective endocarditis are especially important in this group.

During the 18 year study period the recommended prophylaxis for dental procedures that were likely to produce a bacteraemia was a single large intramuscular dose of penicillin given approximately an hour before the proposed procedure. (Our current policy for oral administration of amoxycillin accords with current adult practice.) This same regimen was used as prophylaxis for cardiac catheterisation until 1975, but since then the procedure has been carried out without antibiotic prophylaxis. Only one case of infective endocarditis was attributed to cardiac catheterisation. During the entire study period there were $500-550$ procedures per annum.

Prophylactic measures were used before operation (both on and off bypass) thoughout the study period. They were started one hour before the induction of anaesthesia and were maintained for 7-10 days. The antibiotic regimen used varied considerably throughout the period, and both single and combination policies were used. The choice has been dictated by local microbiological factors, but has always been aimed at providing not only cover against
Gram positive and Gram negative bacteria, but also considerable protection against staphylococci. Penicillin and gentamicin plus one of the cephalosporins were used to provide basic cover.

It is difficult to estimate the incidence of infective endocarditis in congenital heart disease because of the wide spectrum of lesions seen. All types of congenital heart lesions are associated with infective endocarditis, with the probable exception of secundum atrial septal defect. ${ }^{2}$ In simple ventricular septal defect the risk of infective endocarditis is 1-2.4 per 1000 patient years; associated aortic insufficiency increases the risk. ${ }^{2-5}$ After closure of the ventricular septal defect the risk drops but is not completely eliminated. ${ }^{46}$ The risks of infective endocarditis after aortic valvotomy for aortic stenosis and after cardiac catheterisation have been estimated to be 3.8 and $0.02 \%$ respectively. ${ }^{37}$ In patients with a left ventricle to right atrial shunt (Gerbode type ventricular septal defect) the risk is about $20 \%{ }^{8}$ For untreated pulmonary and aortic stenosis the risk of infective endocarditis is 0.2 per 1000 and 1.8 per 1000 patient-years respectively. ${ }^{4}$ Although the risk of infective endocarditis is sometimes reduced after intracardiac repair it is likely to be present for life. The risk depends on the lesion. Although our data do not allow calculation of the incidence of infective endocarditis, the number of postoperative cases in the study suggests that it would be a real and continuing problem for paediatric surgical centres. Furthermore, the risk of a second or third episode of infective endocarditis increases geometrically after the initial infection. ${ }^{9}$

The relative rarity of infective endocarditis in patients under two years of age (except for neonates) has been attributed to absence of dental problems in this group. ${ }^{5}$ Four of our 18 non-operated patients and two in the early cardiopulmonary bypass group were less than two years old when the infection developed; this suggests that infective endocarditis is not a disease limited to older children. Furthermore, dental factors were rarely identified as aetiological factors in septicaemia leading to infective endocarditis in the post-cardiopulmonary bypass group. Although it has been suggested that infective endocarditis of the right heart is less likely to impair haemodynamic function than the left heart infections, this may apply more to rheumatic valvar disease than to congenital lesions. ${ }^{10}$ Infective endocarditis is especially virulent in the presence of a right ventricle to pulmonary artery conduit.

The significantly higher mortality rate for infective endocarditis occurring after cardiopulmonary bypass is likely to be related to the higher frequency that are not Gram positive and to the presence of intracardiac prosthetic material as well as to extra- 
cardiac conduits. The risk is enhanced by a low cardiac output. The main reported causes of death in infective endocarditis during the perioperative period have been uncontrollable congestive heart failure caused by valve perforation and uncontrollable sepsis, which was common before antibiotics became available. ${ }^{1112}$

Death in patients with infective endocarditis may be the result of underlying cardiac problems, of infection, or of side effects of treatment. It may be difficult to judge the relative importance of each. In our series uncontrolled sepsis caused the death of two out of three non-operated patients and aortic insufficiency led to the death of the remaining patient. The deaths associated with sepsis were caused by Escherichia coli and a streptococcus. The early deaths after cardiopulmonary bypass were associated with uncontrolled staphylococcal sepsis (two cases) and to a low cardiac output (two cases). Two of the five deaths among the late cases of cardiopulmonary bypass had sepsis (staphylococcal and fungal); two died after cerebral emboli and the fifth after conduit thrombosis. Three of the nine patients who died after cardiopulmonary bypass had right ventricular to pulmonary artery conduits (vs $4 / 42$ for the series as a whole). The relative risk of death in those with right ventricle to pulmonary artery conduits was 1.3 and that for infective endocarditis caused by a non-streptococcal/non-staphylococcal organism was $3 \cdot 14$. The relative risk if the patient had congestive heart failure at diagnosis of infective endocarditis was 8.36; this was the highest risk for any feature in the study. Other factors associated with a high risk of death were renal failure and previous cardiopulmonary bypass surgery. The overall mortality of $50 \%$ for infective endocarditis after cardiopulmonary bypass surgery for congenital lesions is in the order of that for prosthetic valve endocarditis in adults. ${ }^{11-16}$

Trauma to any epithelial surface especially in the oropharynx and gastrointestinal or genitourinary system can result in bacteraemia. A breach in the endothelium makes the cardiovascular system vulnerable; hence surgical factors such as pacemakers, arterial lines, cardiopulmonary bypass, blood products, and intravenous infusions have all been implicated as the source of infection. ${ }^{2}$ If dental extractions ultimately lead to infective endocarditis they usually do so within two weeks in $85 \%$ of susceptible patients. ${ }^{17} \mathrm{~A}$ delay between symptoms and diagnosis, an inapparent entry point, and previous antibiotic treatment can all obscure the source. In previous reports, including adult patients with native (that is non-perioperative) infective endocarditis, approximately half had no source identified. ${ }^{818}$ In the present study only the early cardiopulmonary cases had a (presumptive) source of septicaemia in every patient. A dental source for the septicaemia, for which prophylactic antibiotics might have been given, was suspected in only one of the 18 cardiopulmonary bypass cases. Furthermore, two patients developed infective endocarditis despite prophylaxis with antibiotics before dental procedures. Fully effective antibiotic prophylaxis may be impossible in certain categories of patients (for example those with low cardiac output and renal failure) whether or not they are treated surgically (bypass or non-bypass) because all the potential sources for infection cannot be identified.

Confirmation of suspected infective endocarditis by blood culture was possible in all but three cases of infective endocarditis, and two of these had already been treated with antibiotics.

We found no significant differences in the frequency of positive blood cultures between the groups. This result is different from previously reported series in which the incidence of negative blood cultures was as high as $20 \% .^{19-21}$ Factors which reduce the blood culture yield include variability in culture techniques, the virulence and growth requirements of the organism, and the site of vegetations. A single dose of antibiotic before admission to hospital can result in negative blood cultures for two weeks. ${ }^{2}$ None the less, our high rate of positive cultures may be related to the particular patient population. It is unlikely that true cases of infective endocarditis with negative blood cultures would have been overlooked for the full course of the illness. Right sided infective endocarditis in adult patients has been cited as a potential cause of negative blood cultures, ${ }^{3}$ but our data do not support this in childhood.

The predominance of organisms of the streptococcus viridans group and Straphylococcus aureus in this study accords with other reports. ${ }^{22}$ An increase in the incidence of staphylococcal infective endocarditis has been reported in adults treated by cardiac surgery. ${ }^{2}$ In our study staphylococcal infections were most common in the non-operated group. The preponderance of non-Gram positive infections in our cardiopulmonary bypass group is, however, reminiscent of adult patients with prosthetic valve endocarditis, another group known to have a virulent clinical course. Knowledge of the greater likelihood of non-streptococcal and non-staphylococcal infective endocarditis patients who have been on cardiopulmonary bypass may be useful in initiating antibiotic treatment for suspected cases before the results of blood cultures are known.

The relative infrequency of most of the classic clinical findings (other than fever) suggests the importance of intensive investigation of fever when 
it is the only symptom in patients susceptible to infective endocarditis. The higher frequency of congestive heart failure in cases of endocarditis occurring soon after cardiopulmonary bypass may be partly related to the greater frequency of congestive heart failure in this group even when infective endocarditis is not present. Fever, which was present in nearly all of our patients, has been reported to be absent in $25-30 \%$ of blood culture positive patients. ${ }^{23}$ This difference may be another characteristic specific to our age group and patient population. Abnormal laboratory results, other than anaemia and leucocytosis, were not sensitive markers for infective endocarditis. These two features are of a low specificity, however. The erythrocyte sedimentation rate and circulating immune complex concentrations were not measured in all patients and these results were therefore not used in this study. These investigations were useful in other series. ${ }^{2}$ Operation alone can increase the erythrocyte sedimentation rate.

Echocardiography showed vegetations in nine of 12 patients studied and is now considered to be a standard part of the initial investigation for infective endocarditis. ${ }^{24} 25$ Vegetations must be more than $2-3 \mathrm{~mm}$ in diameter to be visualised by current echocardiographic techniques. Because vegetations can increase in size repeated examinations are necessary. We now repeat echocardiographic examination every week if this diagnosis is suspected. The weekly study is continued during the early period of antibiotic treatment in confirmed cases, and if the vegetation increases in size antibiotic treatment is reviewed and surgical intervention may be considered.

The frequency of serious and fatal complications of infection and treatment indicate not only the importance of early diagnosis and treatment but also a need for adequate prophylaxis. The frequent requirement for surgical intervention in the late cardiopulmonary bypass group emphasises the virulent course of this type of infective endocarditis. Whereas operation is the only option in many patients (uncontrolled sepsis and recurrent emboli), it can introduce a new set of complications. The morbidity of cardiopulmonary bypass operations in patients with intractable congestive heart failure is high even when active infective endocarditis is not present.

\section{Conclusions}

Several points can be made regarding infective endocarditis in the paediatric population. Any patient with a congenital heart lesion, whether untreated, repaired, or palliated, should be consid- ered at risk for infective endocarditis. There appears to be no time limit for the occurrence of infective endocarditis; for many lesions the risk is probably lifelong. Sensitive clinical indicators of infective endocarditis in children are limited to fever, anaemia, and leucocytosis. The presence of any of these features should raise suspicion in susceptible patients. If infective endocarditis is present blood cultures and echocardiography are very likely to confirm the diagnosis and should be done even when probability of infective endocarditis seems low by other criteria. The source of septicaemia is not definable in most cases, especially when the disease develops late after cardiopulmonary bypass. Totally effective antibiotic prophylaxis is therefore impossible. Non-Gram-positive organisms were more common in cases arising after cardiopulmonary bypass and these cases are more likely to need surgical intervention and more likely to die from the combination of the underlying cardiac lesion, infection, and treatment. The complication rate for infective endocarditis is high for all groups and increases when there is a delay in the initiation of treatment. These points serve to re-emphasise the critical importance of early diagnosis, which can be achieved only by thorough investigation of minimal symptoms and signs, especially after cardiopulmonary bypass surgery.

\section{References}

1 Armitage P. Statistical methods in medical research. Oxford: Blackwell Scientific Publications, 1971.

2 Freedman LR. Infective endocarditis and other intravascular infections. New York: Plenum, 1982.

3 Keith JD, Rowe RD, Vlad P. Heart disease in infancy and childhood. New York: Macmillan, 1978.

4 Gersony WM, Haynes CJ. Bacterial endocarditis in patients with pulmonic stenosis, aortic stenosis or ventricular septal defect. Circulation 1977;56:84-6.

5 Corone P, Doyon F, Gadeau S, et al. Natural history of ventricular septal defect. A study involving 790 cases. Circulation 1977;55:908-15.

6 Shaw P, Singh WSA, Rose V, Keith JD. Incidence of bacterial endocarditis in ventricular septal defects. Circulation 1966;34:127-31.

7 Braunwald E, Swand HJC. Cooperative study on cardiac catheterisation (Monograph 20). New York: The American Heart Association, 1968.

8 Deverall PB, Taylor JFN, Aberdeen E, Waterston DJ. Left ventricular right atrial communication. Ann Thorac Surg 1969;8:498-505.

9 Sipes JN, Thompson RL, Hook EW. Prophylaxis of infective endocarditis: a re-evaluation. Annu Rev Med 1977;28:371-91.

10 Arbulu A, Asfaw I. Infective endocarditis. In: Glenn WWL, ed. Thoracic and cardiovascular surgery. Norwalk: Appleton Century Crofts, 1983.

11 Cohen L, Freedman LR. Damage to the aortic valve as 
a cause of death in bacterial endocarditis. Ann Intern Med 1961;55:562-4.

12 Kaye D. Cure rates and long term prognosis. In: Kaye D, ed. Infective endocarditis. Baltimore: University Park Press, 1976:201-11.

13 Kay JH, Bernstein S, Tsuji HK, et al. Surgical treatment of candida endocarditis. JAMA 1968; 203:621-6.

14 Jamieson MPG, Rees PG, Stark J, de Leval M. Tricuspid endocarditis with ventricular septal defect. Thorac Cardiovasc Surg 1980;28:48-50.

15 Richardson JV, Karp RB, Kirklin JW, Dismules WE. Treatment of infective endocarditis: a 10 year comparative analysis. Circulation 1978;58:589-97.

16 Watanakunakorn L. Prosthetic valve endocarditis. Prog Cardiovasc Dis 1978;22:181-92.

17 Starkebaum M, Durack D, Beeson PB. The "incubation period" of subacute bacterial endocarditis. Yale J Biol Med 1977;50:49-58.

18 Pelletier LL, Petesdorf RG. Infective endocarditis: a review of 125 cases from the University of Washing- ton Hospitals: 1963-1972. Medicine (Baltimore) 1977;46(4):287-313.

19 Pesanti EL, Smith IM. Infective endocarditis with negative blood cultures - an analysis of 52 cases. Am J Med 1979;66:43-50.

20 Editorial. Infective endocarditis with negative blood cultures. $\mathrm{Br}$ Med J 1979;ii:4.

21 Cannady PB, Sanford JP. Negative blood cultures in infective endocarditis: a review. South Med J 1976;69:1420-4.

22 Johnson DH, Rosenthal A, Nadas AS. A 40 year review of bacterial endocarditis in infancy and childhood. Circulation 1975;51:581-8.

23 Teich EM. Afebrile bacterial endocarditis. J Mount Sinai Hosp 1968;35:566-77.

24 Rubenson DS, Tucker CR, Stinson EB, et al. The use of echocardiography in diagnosing culture negative endocarditis. Circulation 1981;64:641-6.

25 Stram J, Becker R, Davis R. Echocardiographic and surgical correlations in bacterial endocarditis. Circulation 1980;62(1):164-7. 